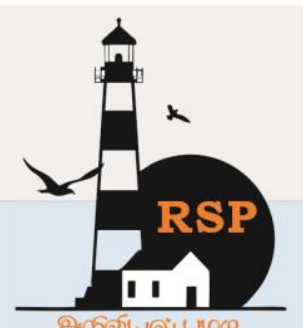

INTERNATIONAL RESEARCH JOURNAL ON ADVANCED SCIENCE HUB

ISSN : $2582-4376$
Open Access

RSP SCIENCE HUB

(The Hub of Research Ideas)

Available online at www.rspsciencehub.com

Special Issue of Second International Conference on Advancements in Research and Development (ICARD 2021)

\title{
Automatic Check Post and E-Toll Payment System
}

Soundharya $B M^{1}$, Yogeshwaran $R^{2}$, Tharanish Krishna $A D^{3}$,Vinitha $V^{A}$

${ }^{1,2,3,4} U G$ Student, Dept. of Electronics and Communication Engineering, SNS College of Technology,

Coimbatore, Tamil Nadu, India

soundharyamoorthi2000@gmail.com ${ }^{1}$,yogeshramesh29@gmail.com²,

tharanishkrishnadurai@gmail.com ${ }^{3}$,vinitha.v1203@gmail.com ${ }^{4}$

\begin{abstract}
The amount of traffic in recent years has gradually risen as a result of the rise in the number of cars. It causes traffic issues, and even in the toll gate system, traffic delays occur, time and fuel absorption is elongated. The automatic toll accumulation system is actually reasonably effective compared to other schemes. This paper has to do with Automatic Check Post, E-Toll Payment System, vehicle theft detection, and intimation to the nearby police station using Radio Frequency Identification (RFID) and Global System for Mobile Communication Module (GSM). The detection is accompanied by a passive Radio Frequency guide. This project is connected with car specifics such as a specific ID stored in the FASTag that is attached to the vehicle. After all, the parameters are essentially implemented by a computer and can be stored in the data bank for a cyclical gap as for timestamp. Specific users have a special ID for their cars. When the car enters the Toll-Plaza, readers read the tag and the tax payment will be deducted from their balance of accounts by using the RFID and GSM modules. In the event of any car being stolen, an authorised customer and a network of RFID scanners located in separate checkpoints, traffic signals, or toll plazas in the city can log in to the server. ATmega328 The Arduino controller must be wired to the GSM network, which allows the user to monitor the device by sending SMS or creating a call and often stops it.
\end{abstract}

Keywords: RFID tag, Database, Unique Code, Radio waves, Latitude, and Longitude.

\section{Introduction}

Automatic Check Post and E-Toll Payment System use Radio Frequency Identification (RFID) that would be added to a toll payment system that seeks to be able to easily identify items in order to provide time efficiency and to make a shift in payment management feasible. When applying for payment automatically, this must obviously be correct and fast for the item to be added. Thus, the use of such a system is predicted to minimize congestion, which often exists ahead of toll doors and lane exits. This is generally attributed to the amount of time spent on automated payment transfers at the toll gate, where the E-Toll payment system will make the toll road operation effective. In addition to the speed of the processing time in the toll door, data protection from the computer used by the customer is also needed, which can be provided by an e-toll using RFID tags. A stolen vehicle at a toll gate can be detected by a GPS-based vehicle monitoring device that monitors the vehicle and transmits tracking data via an SMS. The micro-controller serves as the control head of the machine. When the device is in burglary mode, the registered person will get a warning when filing a report at the police department so that the car record is updated as a theft vehicle. 


\section{www.rspsciencehub.com}

The system contains a GPS modem that records the location of the vehicle in the form of latitude and longitude. This location is also accessed via SMS sent to the user. With the aid of details on latitude and longitude, the user would be able to find the vehicle using the Google map. This device proves useful for transport and travel firms, as they are now able to keep track of their automobiles.[1-6]

\section{Existing Methodology}

The Ministry of Road and Highway Transport made FASTag compulsory as of 1 December 2019. Non-FASTag drivers shall be paying twice the toll fee if they are subject to FASTag-only lanes after 1 December 2019, as provided for in the National Highway Fee (Tariffs and Collection) Regulations, 2008. Also, the insufficient balance on your sticker will get your car blacklisted on the track, and you'll find yourself paying double fees again. The change is part of the Nationwide Electronic Toll Collection Scheme, which seeks to consider the increased flow of traffic, the elimination of congestion, and the collection of cashless tolls. FASTag can be a vehicle tag fitted with an RFID (Radio Frequency Identification) chip. Vehicles, during which the FASTag stickers are mounted on the windshields, may experience toll plazas since the vehicle tag will automatically be scanned to collect tolls digitally. FASTag customers earned 2.5 percent cash back in the year 2019-2020 to enable more people to follow the new framework. Most of the toll plazas across the state are updated to facilitate cashless toll collection. [7-10].

\subsection{Automatic Toll Collection System}

\section{Block Diagram}

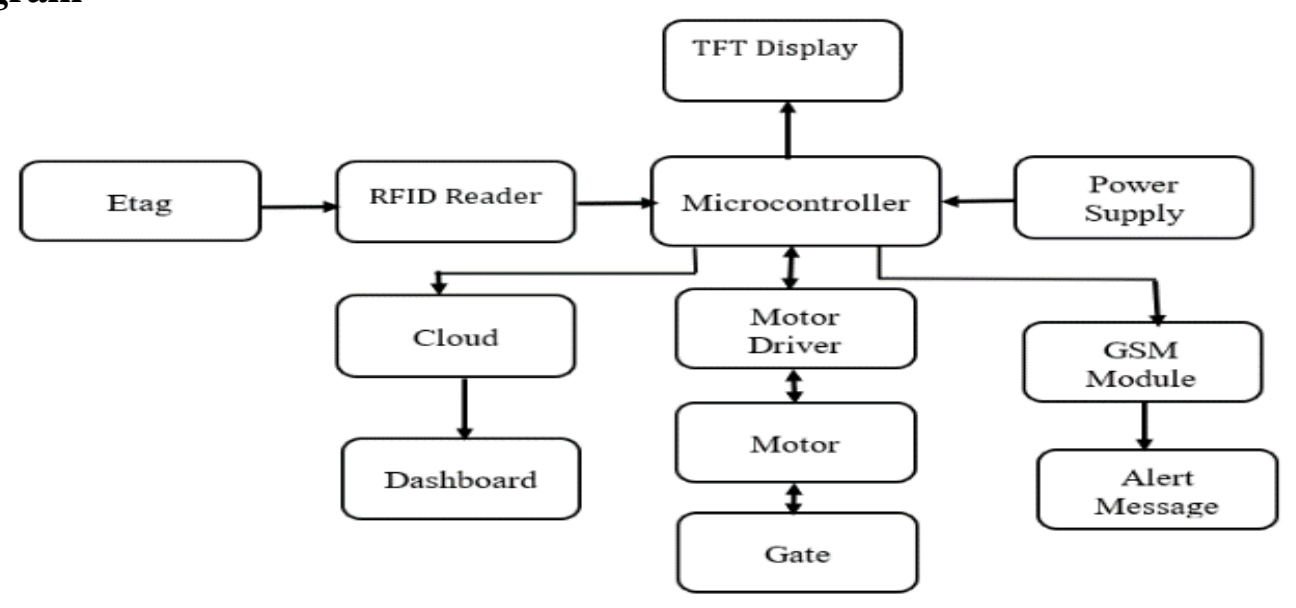

Fig. 1 Block Diagram
The RFID readers on the toll booth will read the prepaid FASTag on the vehicle's windshield, and the respective number will be deducted automatically. If the sticker is not present in the windshield, the cameras mounted at the two sides of the toll plaza take snaps of the front and back number plate.Because each car registration ID is connected to the user's account, the toll rate can be deducted directly from the bank account.

\subsection{Vehicle Theft Detection}

If the car is stolen, the driver files a report on the website with his identification ID and special RFID tag number. Once, the stolen car goes through the toll plaza, if the tag attached to it fits the stolen vehicle tag in the toll booth database, the details will be forwarded to the police station or registered telephone phone.

\subsection{Signal Breaking Avoidance}

A vehicle that violates the traffic signal will be identified by means of a camera placed on the traffic signal poles, and the database will be updated with the required fine number and reported to the traffic police. When the car enters the toll plaza, the amount of the toll will be deducted from the account along with the fine changed in the database.

\section{Proposed Methodology}

This initiative eliminates the complications of passengers paying tolls at toll booths by making them automatic, identifying car fraud, avoiding signal breakage, monitoring speed vehicles. All of these operations are carried out using FASTag, thus saving the time to hold money and documents manually. 


\section{www.rspsciencehub.com}

When the car approaches a transceiver's network coverage, it locates the tag and decodes the code assigned to the unique tag. It is transmitted to the microcontroller at the toll station after decoding. The microcontroller would collect the code and automatically enter the database, and if the vehicle has a legitimate prepaid account at the toll station, the required toll will be deducted from the account and the toll gate will be unlocked to allow the vehicle to move. If the vehicle were stolen, the owner can update the database with its information. When the theft vehicle crosses the tollgate, the tollgate controller software indicates the vehicle may be a theft vehicle, so that the toll gate collector enquires the driving force and, therefore, the microcontroller sends an alert message to the police station or the registered mobile number using GSM. Thus, we could locate the stolen vehicle. If a car has been stolen, the owner will file a report at the police department and change the record as a stolen vehicle. The tollgate controller programme shows that the vehicle was robbed when the robbery vehicle crosses the tollgate, and after that, the toll gate collector cans cross-check the specific code with the driver. If the unique code is wrong, we can recover the stolen vehicle and also send an alert message to the vehicle owner.

\section{Methodology}

The basic solution to this project is the idea behind the functioning of RFID tags, i.e. the identification of objects on which the RFID tag is present, without the requirement for a line-of-sight transponder. In an RFID module, the critical transponder has all the details, the transponder is also called an RFID tag, the information stored is also stored in a binary bit or a number of binary bits, e.g. personal information, medical information or some kind of information stored digitally. Upon arrival in a set of readers, the RFID identifier, i.e. the passive tag, was transmitted to the transceiver. Since passive RFID tags are powerless, they take power from the electromagnetic field that comes from the RFID reader. Usually, the foremost important component of a tag is the chip or microchip. When the tag reaches the reader's RF field, it draws such a lot of power that it can easily access internal memory and transfer the knowledge stored. As soon as the transponder is enabled, the voltage at the transceiver antenna drops due to the RF field. This allows the tag to communicate to the reader and to pass the stored information. The tag is capable of manipulating the amount of power gained from the RF sector, which enables it to modulate the amount of voltage acquired by the transceiver according to the pattern of the bits that it wants to pass to some kind of information.

\subsection{Payment process}

The payment process involved in the toll plaza is fully online mode. In the first step, the user must include the necessary information, such as user name, vehicle number, RFID value, source and destination. In the next step, the registration of their payment will be completed, and then they have to pay the required toll amount depending upon the number of toll gates crossed between the source and destination. The segmentation system we used here is the sharp card sort port. "Here we are using the chip, having the memory uttermost scopes of $4 \mathrm{~K}$ ". The memory in it is the set away measure of cash respect. "Right when the switch is pulverized for the segment the pined for aggregate will be deduced from the memory and the remaining sum is displayed on the systems". When the memory card balance is nil, it is mandatory to receive the card back and proceed with the procedure.

\subsection{Toll Validation}

When the car approaches the toll gate, the RFID reader validates the RFID sticker placed on the windshield. If true, their RFID value checks for matches.

\subsection{Theft Identification}

The RFID system can provide an effective antitheft system. This is often done by retrieving the information that is already stored in the user registration form for toll payment registration. Through doing so, once the theft of the registered vehicle reaches the toll gate, it will be easily detected and a complaint will be sent to the nearest police station, and the latitude and longitude of the stolen vehicle will be sent to the user in the form of an SMS. The vehicle can be easily tracked by the latitude and longitude sent through the SMS.

\section{Flow Chart}

The end-to-end process of the toll payment system for a vehicle that approaches the toll plaza is given in fig. 2 


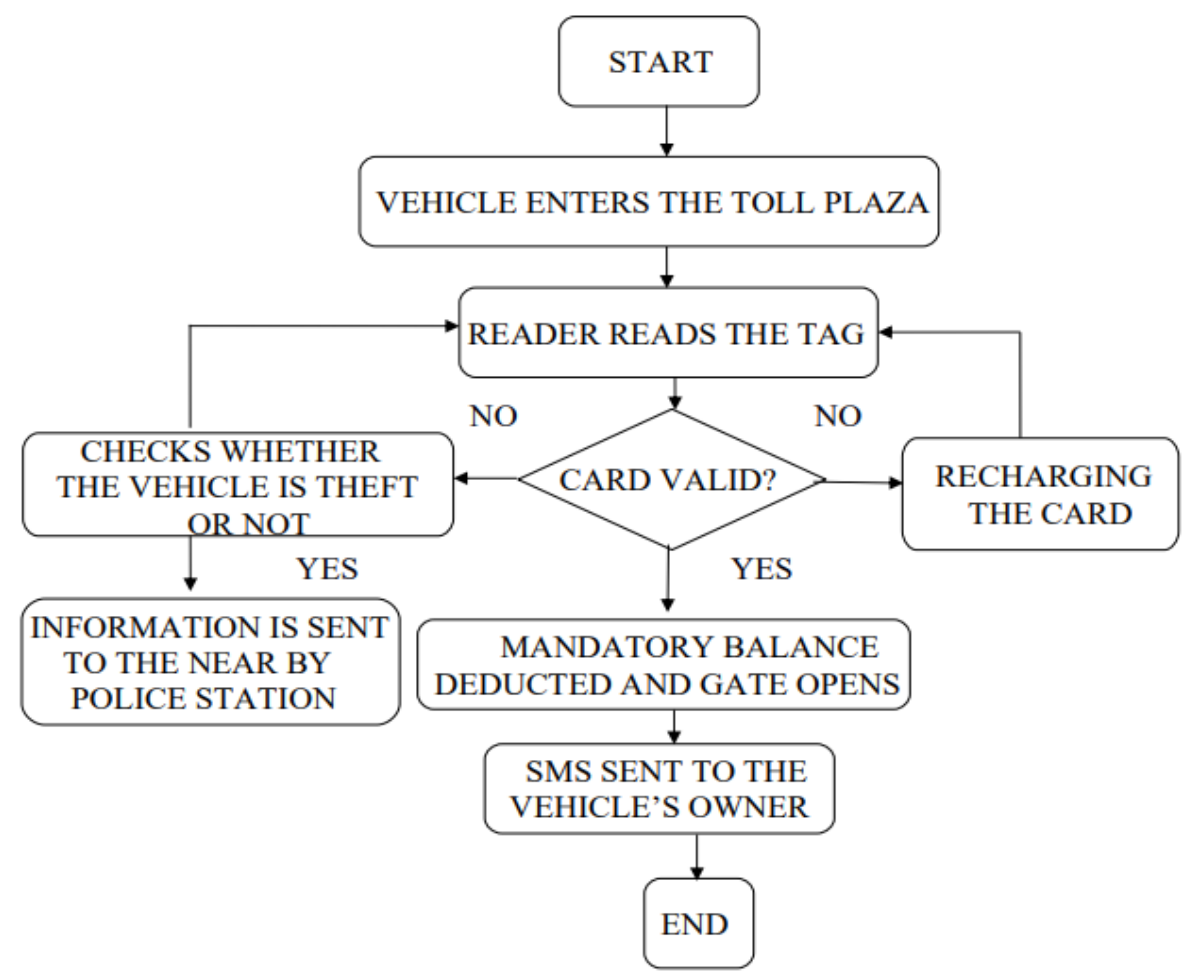

Fig.2 Flow Chart

The Step-by-step procedures followed by the RFID reader to verify whether or not the tag is correct are listed in fig. 3.

\section{Result}

The E-Toll payment mechanism operates as suggested while the vehicle is entering the toll gate with an RFID tag, the EM-18 RFID reader reads the tag as it fits the frequency spectrum, i.e. $125 \mathrm{KHz}$. The reader fetches the data contained in the card, i.e. the unique ID present in the tag is sent to the Arduino where the ID is compared with

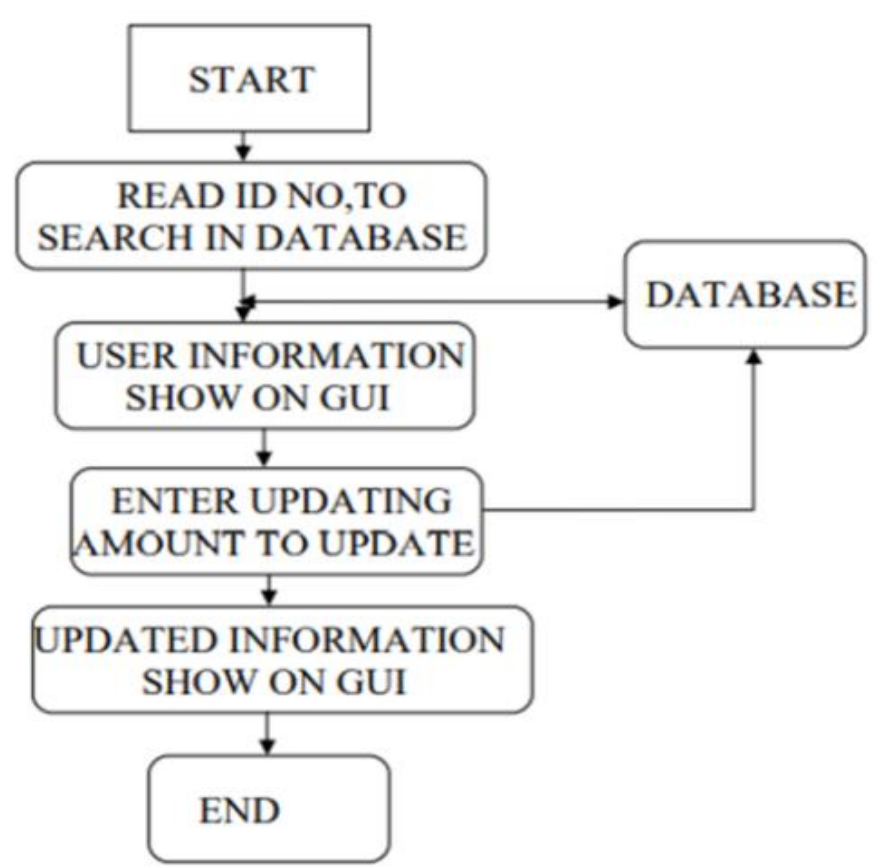

Fig.3 Flow Chart

the databases already present in the toll plaza scheme. If the database holds an ID read from the card, it provides a correct output and then forwards the instruction to the LED to function appropriately, i.e. to blink twice. And then the Arduino commands the engine to start opening the toll gate or barrier for a certain time in such a way that the vehicle with a valid RFID tag can pass 
easily. When there is no passage of the car for longer than 5 seconds, the toll gate locks immediately, so that no other vehicle may enter.

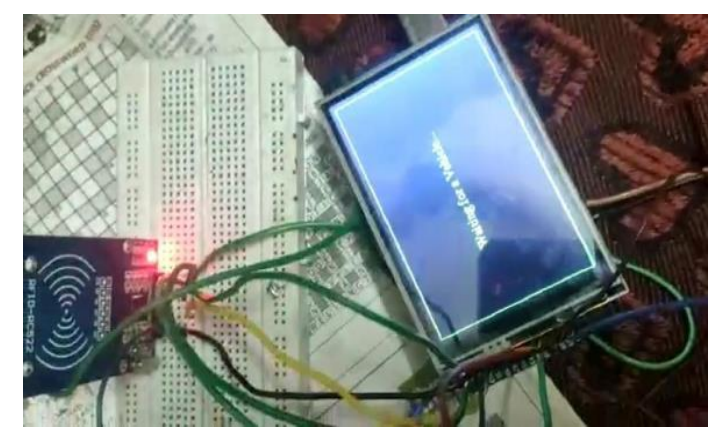

\section{Fig.4. RFID Reader waiting for the vehicle at} the toll gates

Arduino further instructs the GSM module to send a message only to a certain registered mobile number for the approval of the amount deducted and to inform that the amount is appropriate for the deduction. If the card of thecustomer does not have enough to pay, the Arduino refuses the card implying that the card is invalid and orders the GSM module to deliver a message notifying that the card does not have enough to pay for the transaction. Hence, Arduino sends a signal to the LED, so the gate will not be opened for a period.

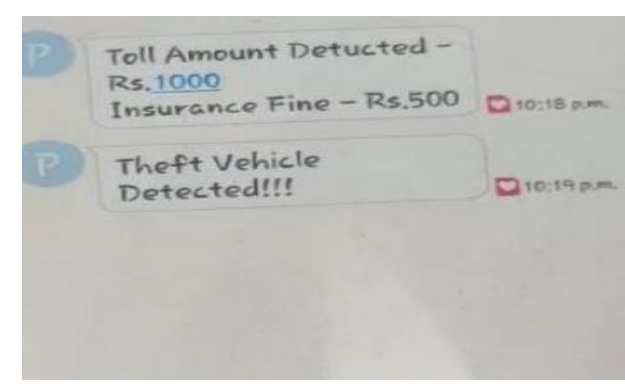

\section{Fig.5. Acknowledgment of toll fare deducted}

If the vehicle is not registered with the FASTag, then the Arduino checks the detail about the vehicle with the databases and directed to the manual counter. While a vehicle with an RFID tag is processed for checking the ID inthe databases, if the vehicle is reported as a theft one, the information along with latitude and longitude of the vehicle will be sent as a message from Arduino through the GSM module to the user's registered mobile number and to the nearby police station. So that vehicle theft can be controlled.

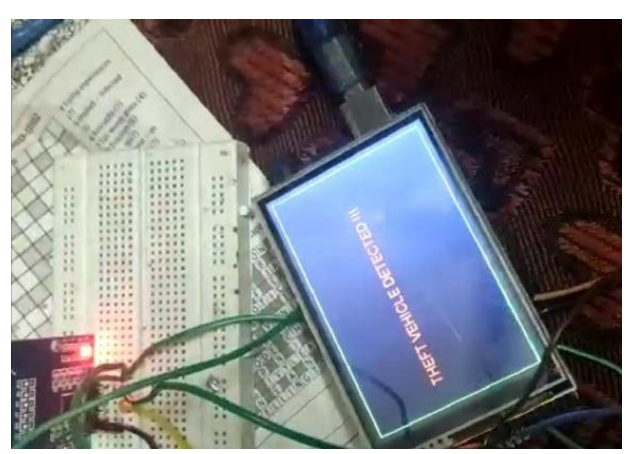

Fig.6. Theft vehicle detection

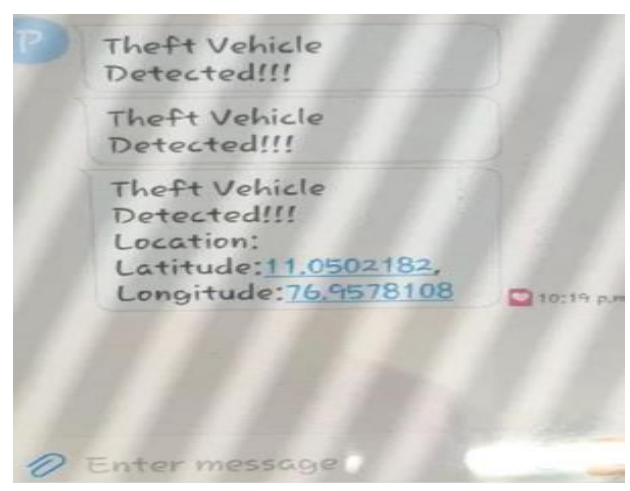

\section{Fig.7. Theft vehicle's latitude and longitude data sent to the user}

\section{Conclusion}

Currently, all highway toll plazas are operated manually where the operator requests the mode of travel, i.e. single or double, from the driver of the vehicle and collects the cash from him/her and provides receipt of the payment. As this manual procedure can be slow, we often encounter traffic jams on busy highways in the toll plazas. The automated toll collection system accelerates the toll collection process and eliminates traffic congestion in the toll plazas. Instead, we are designing a system to provide a fast and secure environment for the collection of tolls and to automatically monitor vehicle movements at toll stations via image processing. Payment can be made simpler by mobile wallets, credit cards, or net banking before hitting the toll plaza through an android programme. Through using image processing, we will not need any smart devices to be mounted in the toll plaza, as the processing can be performed directly from the video feed collected from the CCTV installed in the toll plaza. Besides this, time consumption can also be reduced at the toll plaza. We have introduced a 


\section{www.rspsciencehub.com}

method called Radio Frequency Identification (RFID) "in this paper". This technique will integrate the vehicle's identity using the RFID tag.

\section{Future Scope}

The following are the subsequent scopes that can be flourished using this technology:

Outrage of traffic rules: Further, if RFID readers and speedometer which calculates the speed at shorter distance were developed not beyond the city limit, the corps can easily seize the vehicle which crosses the maximum speed, or which violates the traffic rules by collecting the vehicle's information, recording through the RFID tag present in the vehicle. This technique can be used to observe and trap the people violating rules by overloading their vehicle, replacing speedometers with weight calculators. This in turn makes the work of the traffic cops easier and traffic rules more efficient. Image Processing Approach: The Implementation of Digital Image Processing technology accompanied by the RFID system helps in constructing the Automatic Toll Collection System more effectual, reliable, fasten, and secure for the users and the officials. This is achieved by making use of sensors and a photographic telescope at the toll booth for collecting vehicle's image that enters the toll booth to verify the vehicle's registration number. Later, the vehicle registration number and the tag's unique id is cross checked, so that offences such as switching to the other tag or replacing the number board would not happen. This results in minimizing the work to the traffic cops at the check-post.

\section{References}

[1] Raed Abdulla, Aden Abdillahi, Maythem K. Abbas, "Electronic Toll Collection System based on Radio Frequency Identification System", International Journal of Electrical and Computer Engineering (IJECE), Vol. 08, No. 3, June 2018, pp. 1602-1610.

[2] R. Kavitha, S. R. Srividhya, "Authenticated Toll Collection and Tracking of Vehicles using RFID", International Journal of Innovative Technology and Exploring Engineering (IJITEE), Vol. 08 Issue-8, June 2019.

[3] Mrs. I. Varalakshmi, Mr. D. Abishek, Mr. K. Anbu Suriya , Mr. Harish B.T, "SmartPay Unified Payment System using NFC", International Research Journal of Engineering and Technology (IRJET) Vol. 07 Issue: 10 , Oct 2020.

[4] Manjunat.H ,Velantina.V ,VedaBai.G ,Varshini.m.naik ,Padmavathi.S, "Reduction of traffic at toll plaza by automatic toll collection using RFID and GSM technology", International Journal of Current Engineering and Scientific Research (IJCESR), vol. 06, issue-6, 2019.

[5] AungMyint Win , Chaw MyatNwe , KyawZinLatt, "RFID Based Automated Toll Plaza System", International Journal of Scientific and Research Publications, Vol. 04, Issue 6, June 2014.

[6] Fathima .G1, Jayamala .J, Keerthika .S, "Online Toll Payment System", International Journal of Innovations in Engineering and Technology (IJIET), Vol. 10, Issue 2, 2020.

[7] Kavyashree M, Mamatha M, Manasa N M, Vidhyashree H E, Nagashree R N, "RFID Based Smart Toll Collection System", IJERT, Vol. 08, Issue 11, 2020.

[8] Likhita M, YaliniDevi S, Hanisha K, Chidambara Thanu K, "TOLLZ-E (Online toll system)", International Research Journal of Engineering and Technology (IRJET), Vol. 06 Issue: 04, Apr 2019.

[9] Bharavi Joshi, Kajal Bhagat, Hetakshi Desai, Malvik Patel, "A Comparative Study of Toll Collection Systems in India", International Journal of Engineering Research And Development, Vol. 13, Issue 11, November 2017.

[10]Yash Soni, Akash Bangar, Pranali Ghugal, Kunal Wandhre, Nimish Munishwar, Dr N.V. Chaudhari, "Research paper on E-Toll system with user and vehicle identification", IJARIIE Vol. 04, Issue 2, 2018. 